\title{
Regulations in blockchain sustainable integration into labor relations
}

\author{
Ruslan Dolzhenko ${ }^{1,2, *}$ \\ ${ }^{1}$ Ural State University of Economics, 620144, 8 Marta Str., 66, Ekaterinburg, Russia \\ ${ }^{2}$ Ural Institute of Management - Branch of RANEPA, 620144, 8 Marta Str., 70, Ekaterinburg, Russia
}

\begin{abstract}
The study examines the regulations and laws governing blockchain in the system of labor relations. Labor relations have always been governed and controlled, due to the significant opportunism of the participants and continuous modification. The accumulation of changes should lead to the adaptation of the labor relations regulations. In this regard, the purpose of the work is to investigate the impact of the use of blockchain in the system of labor relations from the point of view of labor law to highlight opportunities and threats, to propose options for normative regulation of the use of distributed ledgers in the world of work. As a result of the study, gaps in labor law have been highlighted that do not allow using the full potential of blockchain. It is proposed to supplement the Labor Code of the Russian Federation with a section that regulates the use of digital technologies in the regulation of labor relations. The key conclusion of the study is that the positive impact of blockchain on labor relations is minimized due to the lack of a legal foundation in this area.
\end{abstract}

\section{Introduction}

Nowadays the system of labor relations undergoes serious changes caused by digital transformation, self-isolation because of COVID-19 pandemic, modification of social relations and many other factors. The contradiction between the need for the changes and adaptation to the challenges, on the one hand, and pursuit of stability accompanied by preservation of labor conditions for all parties, on the other hand, has become especially obvious. Both employers and employees have to adapt to the pandemic reality satisfying the needs of each other, but it is nearly impossible to do it without introducing new approaches at work. It is possible to predict that the legal foundation and regulations will be behind the process that has started in the sphere of labor management in the fields of regulation of working conditions, salary and forms of relations between the parties. This may result in higher risks of opportunism, as there are no mechanisms for its reduction. One of the possible solutions in this sphere is the integration of digital technologies, which are protected against unauthorized alteration, may be quickly adjusted and upgraded to fulfill a significant number of operations. Blockchain, based on distributed ledger, can become such a technology. It attracted much attention in 2017-2018 and they planned that by 2020 the necessary legal mechanisms and norms would have been introduced and blockchain would

\footnotetext{
*Corresponding author: snurk17@gmail.com
} 
be integrated in many spheres of economic, labor and financial relations. Initially, blockchain was defined as a distributed ledger consisting of interconnected transaction blocks. Later on, with the rapid development of information technologies, high demand in protocol security, enlargement of the variety of options, the definition of blockchain has been broadened. Thus, researchers identify three stages in blockchain development (Fig. 1.).

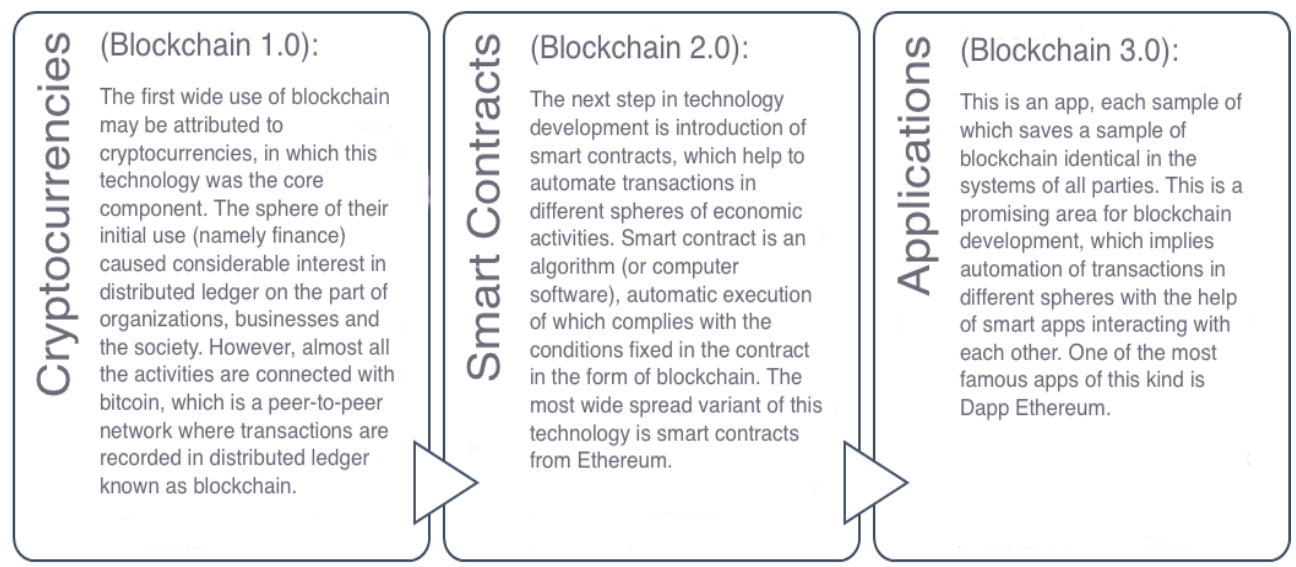

It is important to underline, that blockchain relies on a fundraising method known as ICO (Initial Coin Offering), which is a new cryptocurrency token issued by the company looking for investors; these tokens can be used to pay for products or services of the company. In fact, it is a mechanism of crowd funding technology to attract investors and public attention to the new business.

Proceeding form Google Trends the interest to blockchain technology has stabilized (Fig. 2.).

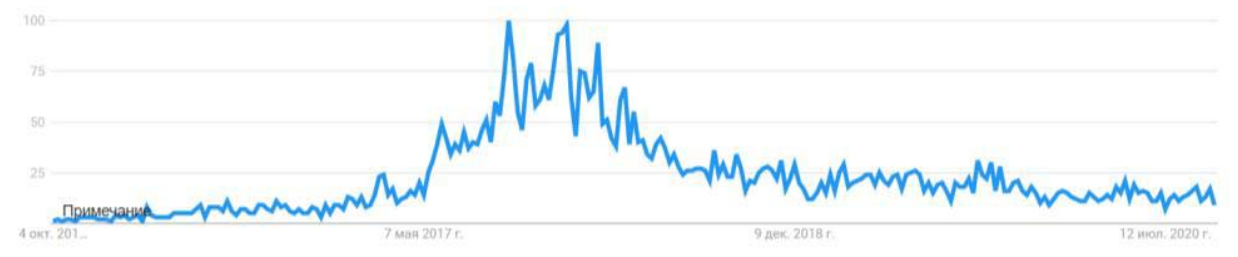

Fig. 2. Dynamics of Google search trends of the word "blockchain" in 2015-2020

The highest interest to blockchain is in China; it is a bit lower in the USA. This information correlates with the data provided by The Next Web, according to which, the USA and China remain to be the leaders in job vacancies in the sphere of blockchain. In the USA, IBM blockchain contains information about genetic resources, data from food industry and health service.

The most advanced countries in the sphere of distributed ledger are Switzerland and South Korea followed by the USA and Japan. The level of this technology development in Russia is rated 7 (while in the world it is 8). 


\section{Materials and Methods}

From the point of view of the New Institutional Economics, opportunism is typical of market participants (it is the desire of a person to satisfy their own needs even under false pretenses) which damages their security, requires establishment of certain departments, principles, rules, systems of punishment to decrease uncertainty of labor relations results. Due to the involvement of a large number of parties (employees and employers) in such relations, it is necessary to provide strict mechanisms of regulation. The solution can be found in the system of statutory regulation of labor relations on different levels, from macro-level to micro-level. Some civil rights in the field of labor activities are to be found in the Constitution of the Russian Federation. The main source for labor standards and norms is The Labor Code of the Russian Federation.

There are three parts in the employment and labor law:

- The general part of employment and labor law that comprises norms making the basis for all kinds of labor relations: goals, topic area, principles, sources, parties, etc.;

- The special part of employment and labor law that includes norms that regulate certain areas of labor relations (salary, job security, labor discipline, working time, etc.);

- The specific part of employment and labor law that contains the norms relevant for certain groups of people or professions (young people, doctors, teachers, etc.).

Noteworthy is the fact that there are many scientific articles published in Russian journals that discuss blockchain in employment and labor law. Based on the analysis of scientific papers, we can provide the following classification of the works in this research area (Table 1.).

Table 1. Topics of the most important studies on blockchain in labour relations

\begin{tabular}{|l|l|l|l|}
\hline $\begin{array}{l}\text { Part of } \\
\text { employment and } \\
\text { labor law }\end{array}$ & The general part & The special part & The specific part \\
\hline Authors & $\begin{array}{l}\text { DolzhenkoR.A. [3, 4], } \\
\text { Prozhennikova A.N. } \\
\text { [10], Leskina E.I. [9] }\end{array}$ & $\begin{array}{l}\text { EvlampievYa.A.[6], } \\
\text { Zakharov D.K. [7], } \\
\text { Kolupayev S.V. [8] }\end{array}$ & $\begin{array}{l}\text { Gracheva A.A., Dagayev } \\
\text { A.A. [2] }\end{array}$ \\
\hline Topics & $\begin{array}{l}\text { Blockchain in labor } \\
\text { relations; Blockchain } \\
\text { platforms in labor } \\
\text { management; Blockchain } \\
\text { in labor and employment } \\
\text { sphere }\end{array}$ & $\begin{array}{l}\text { Blockchain in labor } \\
\text { remuneration; personnel } \\
\text { policy and blockchain; } \\
\text { Labor safety }\end{array}$ & $\begin{array}{l}\text { Competencesofprojectma } \\
\text { nagers in blockchain } \\
\text { sphere }\end{array}$ \\
\hline
\end{tabular}

In our opinion, integration of blockchain in labor law will cause changes in all three blocks. On the first stages of integration, the general part will become the most liable to change as it will require amendment because of the change of legislation (the right will be replaced by technology). The special part of the employment and labor law will be affected by the changes as well after a widespread introduction of smart contracts [11]. The specialized part of the law will be the least affected by the changes, as the work of specific categories of employees will not be seriously modified.

Nowadays some virtual activities are recognized and classified in law. For instance, making an agreement in a couple of clicks in the Internet is not an extraordinary phenomenon. Many people and companies use the function of automatic payment that helps to program economic transactions. Another example is expression of one's opinion in the net that can lead to legal consequences in case of violation of somebody's rights. Some articles in the Criminal Code of the Russian Federation mention such aggravating circumstances as the use of information and communication systems to commit a crime [1].

The most flexible code form the point of view of digital transformation is the Civil Code; the Criminal Code goes next. Unfortunately, Labor Code is one of the most 
conservative laws. The absence of common practice of blockchain integration in labor management sphere brings to naught the chances to settle controversial issues on the basis of conflicts-of-law principles.

Blockchain implies concurrence of the will of the parties at the moment of network entry, after that all the necessary decisions are made automatically via the algorithms of smart contracts. Blockchain is also required in case a party wants to withdraw. Any changes in the chain of actions between the entry and withdrawal are forbidden, which is the peculiar feature of this technology. However, sometimes there appear rule changes in transaction blockchain known as "Hard-fork" (a complete change of rules that requires upgrade of the software). Due to this fact, researchers discuss the need for contract law transformation, as smart contracts made without the immediate participation and control of people cannot be treated as legal in terms of traditional approaches in law [12]. The main feature of blockchain that the costs of the third party and experts involvement are replaced by the costs of computational capacity necessary for verification of different blocks in the chain. So, economic advantages of blockchain are transaction cost reduction, simplification of the procedures of bargaining and its protection from unauthorized alterations. Timestamps and encrypting make blockchain a system that ensures stability of cooperation and decreases opportunism of both employers and employees; moreover, the state acquires flexible opportunities in control and monitoring.

One of the problems accompanying blockchain integration in labor relations is that digital transformation eliminates the distinctions between different areas of law; but until the technology of distributed ledger is introduced in all kinds of legal relations, this problem will not affect labor relations sphere. There is a serious need for some common denominators that will help to determine unified algorithms of relations, guarantees and consequences.

Conservative part of society will become a deterrent to digital transformation of labor relations. Identification of advantages of such transformation may help to overcome its rejection. In this case the right to be forgotten should be mentioned, as well as the right to be offline outside the opening hours (or beyond working hours). In many countries it is common practice that an employee cannot be contacted by their employer beyond their working hours or at weekends. In Russian, such practice is being discussed, but there is no legal basis to regulate it yet.

In our opinion, development of the legal foundation and statutory regulation of blockchain in different spheres must be multifaceted and integral; it should appear in the most liable to digital transformation areas of social life. Among them are blockchain technology itself and smart contracts as its variant (peculiarities of their use in different spheres must be paid special attention to; "regulatory sandbox" may help to experiment in this area), different cryptocurrencies on blockchain basis (approaches to their control must be worked out and activity of decentralized organizations must be regarded), new financial systems (development of payment services, perfection of digital financial tools and information security).

It is necessary to introduce and define the concept "labor token", which is a digital asset, a record of labor activity in a blockchain according to which a smart contract algorithm can perform a counter transaction in reference to a contractor. In other words, a record of this token in blockchain provides access to extra functions of blockchain. Depending on the kind of work (unique and non-recurrent or typical and recurrent) labor tokens can be unique (non-interchangeable) or utilitarian (able to be exchanged on tokens of other services).

The place of blockchain in the system of social and labor relations is presented in Fig.3. 


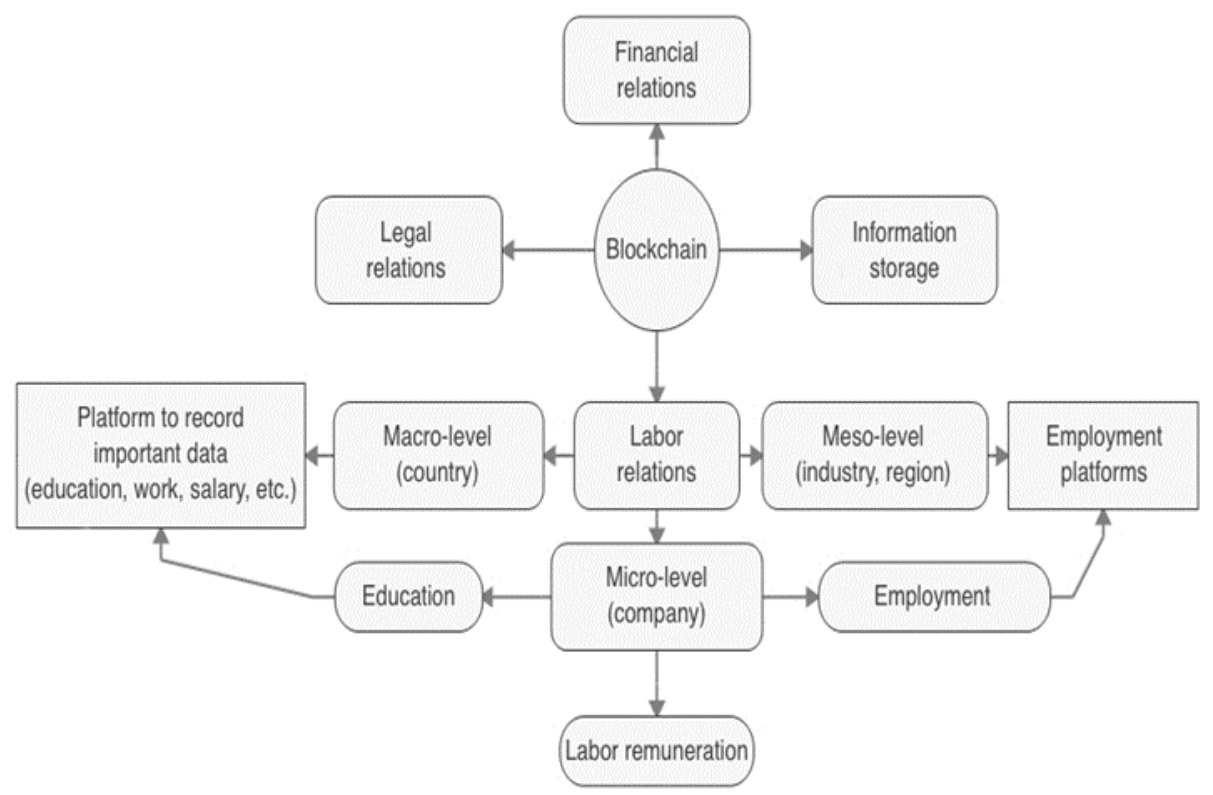

Fig. 3. Place of blockchain in the system of social and labor relations

As shown in the picture, blockchain may be integrated in any sphere of social and labor relations (employment, education, remuneration, promotion and others). However, the question that remains is how to expand the sphere of use of this technology: should the state initiate it with the help of its inclusion in the general part of employment and labor law that will govern all parties or should it be implemented on the level of industries, companies and areas being included in the special and specialized parts of employment and labor law? At this point it seems that both variants are possible.

\section{Results and Discussion}

Analysis of the current possibilities of blockchain integration in the system of labor relations makes it possible to single out the main problems:

1. Absence of a unified processing center responsible for recording of labor transactions and their consequences in the multiple interaction network.

2. Absence of a unified methodological center responsible for standardization of blockchain integration in different areas of social and labor relations.

3. Absence of labor rights protection of the parties involved in relations on the basis of blockchain.

4. Possibility of fraudulent behavior of the parties involved in labor relations on the basis of blockchain.

5. Absence of the regulation of legal succession in blockchain-based labor relations in the traditional system of labor institutions.

Different solutions of these problems can be found:

1. Allocation of responsibility for blockchain integration in social and labor relations to a certain institution of development, for example, the Major Financial Institution 
(VEB.RF) that, for inexplicable reasons, has lost its interest in technologies. It is possible to design a white-paper informing about the basic principles of blockchain integration into the system of social and labor relations.

2. Establishment of a unified processing center to record all transactions, facts and parties' characteristics (including employees, employers and partnerships) in one place. It could be done of the basis of the Pension Fund of the Russian Federation (PFR).

3. Stimulation of design and implementation of various projects based on blockchain into labor management worked out by different parties (organizations, employees, employment agencies, labor unions and employers).

4. Identification of priority spheres in which blockchain can me integrated; development of a road map to expand the usage of blockchain [5]. It should be introduced not only in financial and insurance activities, transportation and storage, public administration, health service and manufacturing, but also into social and labor relations.

5. Development and pilot implementation of software based on blockchain technology in the sphere of labor relations, for example, a unified education document register, which will help to reveal fake certificates and diplomas.

6. It is important to include specific parts in the Labor Code of the Russian Federation because of the rapid changes of labor relations under the influence of digital transformation (electronic labor record books, smart labor contracts, online work, etc.) that will govern the use of digital technologies in labor relations.

\section{Conclusions}

Blockchain has a high potential in many spheres, it can be integrated pursuant to agreement between the parties, however, there is no judicial practice in this area in Russia. A system based on blockchain that, apart from others, includes cryptocurrencies and ICO is not governed by the law and thus its integration may cause certain problems. The future prospects of this technology development may be found in the form of labor tokens used to involve different resources. Due to the absence of the legal foundation for blockchain in labor relations, it is important to follow the principle of "fair practices" which should be worked out on the basis of blockchain integration experience collected in other spheres where this technology is currently used. Thus, it is important to design a white paper (a short digest describing the essence of this technology) which should include the principles of blockchain operation in labor management, the role and value of tokens, prospects for development and limitations of the project, as well as the results of its independent assessment by external reviewers belonging to different areas of labor relations.

In any case, it is possible to conclude that there is a necessity to make amendments in the Labor, Criminal and Civil Codes of the Russian Federation, caused by expansion of blockchain in different spheres. Nowadays, blockchain is integrated only by the most advanced market players; in the nearest future, however, it will be adopted by many other organizations which will require revision of the legal foundation of different kinds of social relations.

\section{Acknowledgements}

The reported study was funded by RFBR according to the research project № 19-01000785 . 


\section{References}

1. K.I. BrykinFin.Law,39 (2018)

2. A.A. Gracheva, A.A. Dagayev Information Soc., 86 (2019)

3. R.A. Dolzhenko, Economic Theory J., 488 (2018)

4. R.A. Dolzhenko, ManagementinRussiaandAbroad, 59 (2019)

5. Roadmap for development of "end-to-end" digital technology "Distributed ledger" (2019)

6. Ya.A. Evlampiev, Intellectual Resources for Regional Dev., 362(2019)

7. D.K. Zakharov, Management of the Personnel and Intellectual Resources in Russia , 74 (2019)

8. S.V. Kolupayev, Bul. ofCont. Research, 26 (2019)

9. E.I. Leskina, Jurist, 25 (2018)

10. A.N. Prizhennikova, Educ. and Law, 216 (2019)

11. A.I. Saveliev, Zakon, 94 (2017)

12. A.I. Saveliev, Civil Law Review, 32 (2016)

13. M. Swan, Blockchain: Blueprint for a New Economy (2017) 